\title{
Assessment and comparison of technological variants of the sodium tripolyphosphate production with the use of multi-criteria analysis
}

\author{
A. Makara ${ }^{1}$ (D) A. Generowicz ${ }^{2}$ - Z. Kowalski ${ }^{3}$
}

Received: 5 October 2017 / Revised: 3 June 2018 / Accepted: 12 June 2018 / Published online: 18 June 2018

(c) The Author(s) 2018

\begin{abstract}
Sodium tripolyphosphate, a condensed phosphate applied in various industries, can be produced according to a new dry single-stage method or a classic spray drying two-stage method. To compare variants of sodium tripolyphosphate production, three multi-criteria methods (Borda, compromise programming and analytical hierarchy process) were applied. Assessment criteria of individual—best available technologies not entailing excessive costs options of sodium tripolyphosphate production and complex quality assessment calculation results allowed for the determination of a decision matrix for a choice of sodium tripolyphosphate production technology based on the applied decision methods. Applying the above methods allowed for ordering of the variants of tripolyphosphate production from the most to the least advantageous. The use of various criteria types (technological options and indices for complex quality assessment) as evaluation criteria in multi-criteria analysis allowed for an independent evaluation of the technology. Calculations from Borda and compromise programming methods showed that, in all cases, the assessment criteria used reached the highest possible level for dry single-stage technology for sodium tripolyphosphate production. Results obtained by analytical hierarchy process method confirmed the conclusions from Borda and compromise programming methods. Ranking of the developed technological solutions indicated the dry single-stage method of sodium tripolyphosphate production to be the advantageous technological variant.
\end{abstract}

Keywords Analytical hierarchy process $\cdot$ Assessment indices $\cdot$ Borda method $\cdot$ Classic spray method $\cdot$ Dry single-stage process

Abbreviations

AHP Analytical hierarchy process

BATNEEC Best available technologies not entailing DSM excessive costs

STPP Sodium tripolyphosphate
CM Technological variant of STPP production by the classic spray method Technological variant of STPP production by the dry single-stage method

\section{Introduction}

Sodium tripolyphosphate $\mathrm{Na}_{5} \mathrm{P}_{3} \mathrm{O}_{10}$ (STPP) is a condensed phosphate that plays an essential role, mostly in the synthetic detergent sector. It is the main component of detergents in laundering and dishwashing (industrial, institutional, and domestic). STPP applied as a filling material and supplemented with surfactants acts as a very efficient detergent.

Sodium tripolyphosphate has been applied as a dispersing agent in ceramic processing and can also be used as an inexpensive plasticizer in cement-based materials (Goberis et al. 2005; Ltifi et al. 2011; Tan et al. 2014). STPP finds applications in the food industry as an additive to meat products (Owen and Will 1992; Aksu and Alp 2012), as an additive to seafood (Gonçalves and Ribeiro 2008), and as a conservation 
agent of foodstuffs, for example, fruit juice or milk. With an increase in STPP applications in industry, there is also an increase in demand for it, and the global sodium tripolyphosphate market is expected to increase up to 8.1 billion USD in 2022 (Market Research Future 2017). About 70\% of the total demand for STPP has been recorded in Asia-Pacific, European, and Latin American countries (Global Industry Analysts Inc. 2017).

Production of sodium tripolyphosphate can be carried out by two technological variants: dry single-stage and classic spray methods. Sorting and concentration of raw materials depend on the choice of the technological variant and on the quality requirements arising from its application (Makara and Kowalski 2013; Kowalski and Makara 2014). Impurities, present in raw materials, may accelerate or retard the progress of the total technological process or affect some its stages. The effect of impurities on the phase composition of STPP depends on the type of impurity, concentration of phosphoric acid, and calcining temperature (Kijkowska et al. 2007; Makara et al. 2011). The formation of anhydrous $\mathrm{Na}_{5} \mathrm{P}_{3} \mathrm{O}_{10}$ begins within a temperature range of $200-250{ }^{\circ} \mathrm{C}$. The rate of reaction increases with the temperature. Depending on the heating (calcining) temperature, STPP appears in one of the anhydrous monoclinic forms: low-temperature $\mathrm{Na}_{5} \mathrm{P}_{3} \mathrm{O}_{10}$-II (Form-II), below $400{ }^{\circ} \mathrm{C}$, or high-temperature $\mathrm{Na}_{5} \mathrm{P}_{3} \mathrm{O}_{10}-\mathrm{I}$ (Form-I). The phase transition, a process that is complex and not entirely described in the literature, has been observed in a wide $\left(450-500{ }^{\circ} \mathrm{C}\right)$ temperature range. This transformation is usually not complete, and it is commonly found that STPP heated above $500{ }^{\circ} \mathrm{C}$ contains a small percentage of low-temperature Form-II (Van Wazer 1958). Form-I and Form-II content in STPP may be regulated through a suitable choice of calcining temperature, resulting in a final product with a predominant amount of Form-I or Form-II. It is very difficult to obtain Form-I or Form-II as a single phase without contamination by at least few percent of the other STPP form or by other phosphates (Van Wazer 1958; Toy 1973).

Multi-criteria analysis is a method that indicates points in the decision-making process allowing for the choice of a technological solution. Criteria that include as many aspects of the technological process as possible have to be preliminary defined (Maxim 2014; Govindan et al. 2015; Matzen et al. 2015). Criteria on the basis of which the decision is made to choose a particular variant of technology are treated as a starting point in multi-criteria analysis. This analysis is performed by different methods that enable the most advantageous solution, which can be the most unique, rational, and/or effective (Zopounidis and Doumpos 2002; Løken 2007; Kahraman 2008). Multi-criteria analysis has been applied to different areas of activity, particularly in environmental protection (Linkov et al. 2006; Huang et al. 2011; Mardani et al. 2015; Gaska and Generowicz 2017).
In this work, multi-criteria analysis was applied in order to choose the most advantageous technological variant of sodium tripolyphosphate STPP production. Multi-criteria analysis, using an assessment of particular BATNEEC (best available technologies not entailing excessive costs) options and complex quality assessment indices as the criteria of STPP production, made it possible to write a decision matrix for the choice of technology using the following decision methods: Borda, compromise programming, and AHP. The research was conducted in the years 2013-2016, within the framework of collaboration between the Cracow University of Technology and Energy Economy Research Institute of the Polish Academy of Sciences Kraków.

\section{Materials and methods}

\section{Methods for assessment and comparison of technological variants of the production of sodium tripolyphosphate with the use of multi-criteria analysis}

\section{Comparison of sodium tripolyphosphate production methods}

In the classic spray method, STPP is obtained by a multistage process of dehydration of a phosphate mixture equivalent to a molar $\mathrm{Na}_{2} \mathrm{O} / \mathrm{P}_{2} \mathrm{O}_{5}$ ratio of 5:3. Production consists of phosphoric acid neutralization (wet process) and heating (dry process). In the wet process, phosphoric acid (thermal or purified "extraction" phosphoric acid) is neutralized with sodium hydroxide or carbonate in an amount necessary to obtain a solution of orthophosphates with a molar $\mathrm{Na}_{2} \mathrm{O}$ / $\mathrm{P}_{2} \mathrm{O}_{5}$ ratio of 5:3. The solution so obtained undergoes dehydration through a spray drying method. In the dry process, the dehydrated mixture of phosphates is calcined in a rotary kiln to obtain the final product of sodium tripolyphosphate $\left(\mathrm{Na}_{5} \mathrm{P}_{3} \mathrm{O}_{10}\right)$. The product undergoes milling, sieving, and packing. Combustion gas from a rotary kiln passes through a dedusting bag filter, and then is recycled into the process. The classic spray method requires more energy for drying and calcining of phosphates. Higher energy consumption arises from the necessity of using diluted phosphoric acid in the neutralization process (Makara et al. 2016).

In the dry, single-stage method, concentrated phosphoric acid $\left(\sim 75 \% \mathrm{H}_{3} \mathrm{PO}_{4}\right)$ is neutralized with sodium carbonate, then some proportion of the final STPP-product is recycled and the mixture obtained is dried and calcined in a rotary kiln in a single technological operation. STPP recycling improves flow rate of the product and protects against agglomeration of the powder, and also facilitates the transport of the mixture into a rotary kiln, where the orthophosphates are condensed into pyrophosphates and converted 
into the final product of sodium tripolyphosphate. The dry, single-stage method, in which the expensive spray drying operation has been eliminated, is less expensive than the classic spray method (Kowalski and Makara 2014).

A technological diagram, where parameters of STPP production for dry single-stage and classic spray methods are specified, is presented in Fig. 1.

\section{Selection of criteria and methods of criteria assessment}

The first method for the choice of criteria was BATNEEC. Using the BATNEEC method, two essential elements were subjected to assessment: first, accordance of the examined technology with the BAT (best available techniques) standard, indicating the best technical solution that guarantees the minimum environmental impact of hazardous materials; and, second, cost-effective production. The options under assessment underwent rating by experts. The scale of scoring was 0-10 points within each of the criteria (Table 1). The sum of the mean estimations of the criterion was used to make an assessment of the options (Kowalski 2001).

The second method applied for comparative assessment of both analyzed methods of STPP production was a complex quality method qualitatively characterizing compared technologies. The aim here was to make a choice of the better one.

The assessment of the complex quality of a substance (also a technology) comprises quality features (" $n$ " could be any number). One resultant number can determine an entity characterized by numerous quality features (Kowalski and Makara 2017). Therefore, complex quality is a function of quality features.

The assessment of technological quality comprised three steps of partial expert assessments; technical level, reduction degree of environmental hazards, and economics of the enterprise (Kowalski et al. 2012, 2015). Particular criteria assessing the level and efficiency of effects of a solution were classified as 0 (zero), 1 (low), 2 (medium), or 3 (high). The arithmetic mean of the points of the individual criterion resulted in its partial assessment. In turn, the arithmetic mean of the technical, environmental, and economic assessments resulted in a value of the complex quality of the technology. The rating of solutions qualified as advantageous should have amounted to more than 1.5 points. The final assessment was supplemented with a possibility of another competitive technology or an appearance of new equipment ( 0 or 1 ).

For the assessment of the analyzed solutions, the following function was applied:

$Q_{\text {mean }}=\frac{a_{1} \cdot W_{1}+a_{2} \cdot W_{2}+a_{3} \cdot W_{3}}{3}$

where $a_{1}, a_{2}$, and $a_{3}$ are degrees of validity, and $W_{1}$ is the value of the technical assessment of the individual solution, $W_{2}$ the value of the environmental assessment, $W_{3}$ the value of the economic assessment, and $Q_{\text {mean }}$ the final assessment of the individual solution.

The results of the technical, environmental, and economic assessments are presented in Table 2. The results of the
Fig. 1 Flow sheet of STPP production methods: classic spray method (CM) and dry singlestage method (DSM)

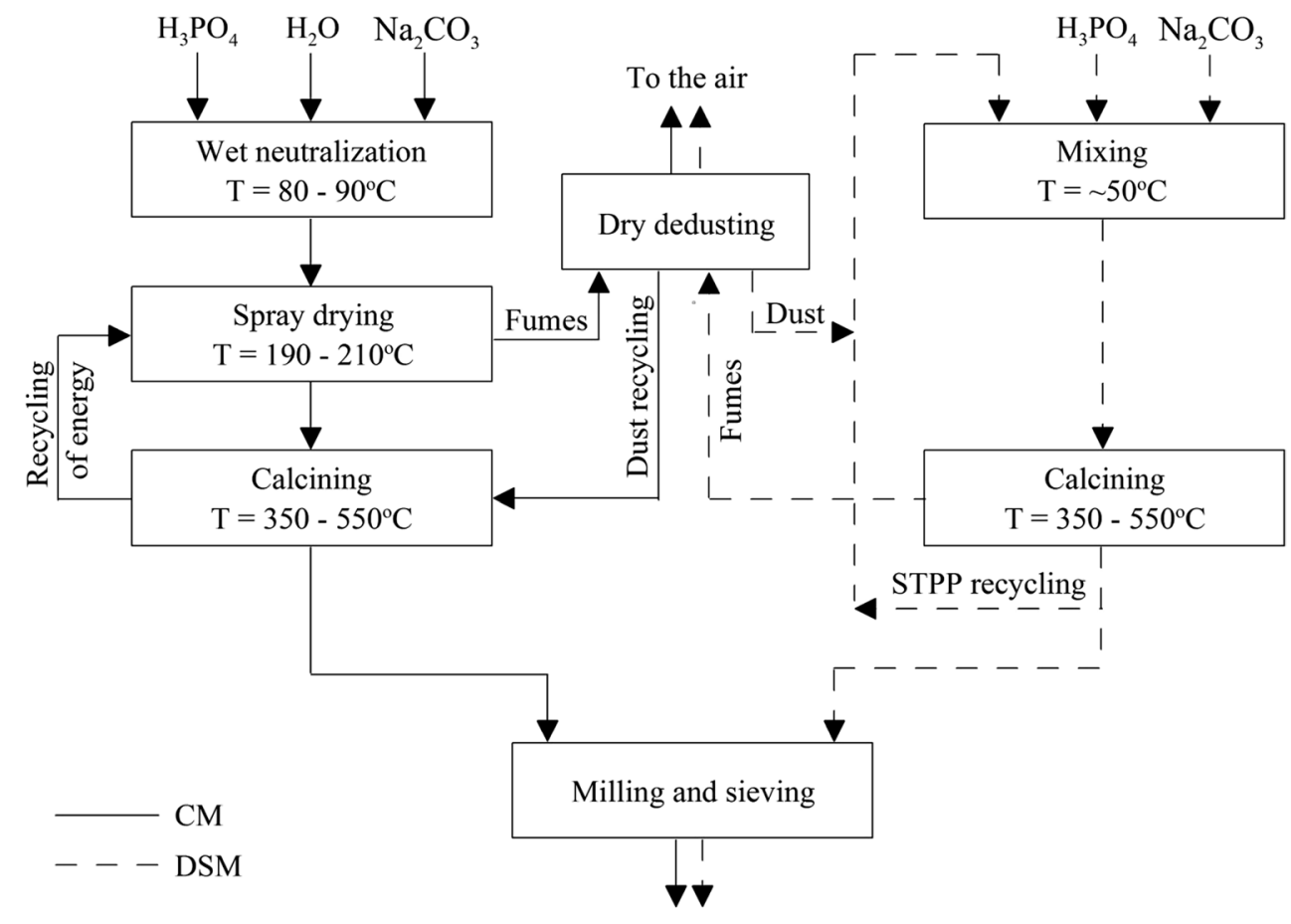

Sodium tripolyphosphate product 
Table 1 Criteria and evaluation of individual BATNEEC options for two variants of STPP production

\begin{tabular}{|c|c|c|c|c|}
\hline \multirow[t]{2}{*}{ Criteria group } & \multirow[t]{2}{*}{ Criteria notation } & \multirow[t]{2}{*}{ Criteria of evaluation } & \multicolumn{2}{|c|}{$\begin{array}{l}\text { Scoring of variants of TPFS } \\
\text { production (points) }\end{array}$} \\
\hline & & & $\begin{array}{l}\text { Classic } \\
\text { method } \\
(\mathrm{CM})\end{array}$ & $\begin{array}{l}\text { Dry single-stage } \\
\text { method (DSM) }\end{array}$ \\
\hline \multirow[t]{9}{*}{ Sustainable development (SD) } & SD1 & $\begin{array}{l}\text { Consistency with the objectives of sustainable } \\
\text { development }\end{array}$ & 4 & 6 \\
\hline & $\mathrm{SD} 2$ & $\begin{array}{l}\text { Consistency with programs of national } \\
\text { economy }\end{array}$ & 5 & 5 \\
\hline & SD3 & Consistency with EU programs & 3 & 5 \\
\hline & SD4 & Degree of adaptation to local conditions & 7 & 8 \\
\hline & SD5 & Improvement of relations with consumers & 5 & 7 \\
\hline & SD6 & Improvement of relations with the public & 7 & 7 \\
\hline & SD7 & Required legal authorizations & 6 & 7 \\
\hline & SD8 & Availability of technology & 9 & 9 \\
\hline & SD9 & Degree of difficulty and implementation time & 7 & 9 \\
\hline Summary assessment of the group & & & 53 & 63 \\
\hline \multirow[t]{4}{*}{ Implementation Efficiency (IE) } & IE1 & Value of investment outlays & 5 & 9 \\
\hline & IE2 & Efficiency of technology & 5 & 9 \\
\hline & IE3 & Risk of implementation & 6 & 6 \\
\hline & IE4 & Product quality and stability & 8 & 8 \\
\hline Summary assessment of the group & & & 24 & 32 \\
\hline \multirow[t]{8}{*}{ Economic $(\mathrm{Ec})$} & Ec1 & Management of by-products (wastes) & 0 & 0 \\
\hline & $\mathrm{Ec} 2$ & Amount and use of generated heat & 3 & 8 \\
\hline & Ec3 & Substitution of natural resources by waste & 0 & 0 \\
\hline & Ec4 & $\begin{array}{l}\text { Environmental assessment of the quantity and } \\
\text { quality of emissions }\end{array}$ & 5 & 6 \\
\hline & Ec5 & $\begin{array}{l}\text { Environmental assessment of material con- } \\
\text { sumption }\end{array}$ & 5 & 5 \\
\hline & Ec6 & Formation of secondary waste & 7 & 7 \\
\hline & Ec7 & Reduction in toxicity degree of waste & 0 & 0 \\
\hline & Ec8 & $\begin{array}{l}\text { Degree of modernity in comparison to the } \\
\text { global level }\end{array}$ & 5 & 9 \\
\hline Summary assessment of the group & & & 25 & 35 \\
\hline Summary assessment of BATNEEC [points] & & & 102 & 130 \\
\hline
\end{tabular}

assessment of the technical level of the analyzed proposals of the new technological solution (30 points) were significantly higher than the assessment of the classic technology variant (19 points). The environmental results of the newly proposed technological solution (27 points) were also higher than those of the classic method (16 points). The economic assessment of the discussed solutions gave results of 10.5 points for the classic method and 16 points for the dry single-stage method.

The total assessment of the technological quality methods of STPP production showed that a higher rating was obtained in the case of the dry single-stage method (47.67 points). The classic method (29.33 points) was lower by about $40 \%$ than the dry single-stage one. These results indicate that high technical and economic progress may be achieved after the dry single-stage method is implemented in industrial practice (Kowalski and Makara 2017). The assessment of the two methods of STPP production is summarized in Table 2.

\section{Choice and description of the methods of multi-criteria analysis applied in the assessment}

Results from the BATNEEC and complex quality assessment methods were used as a basis for multi-criteria analysis, in which the formulated tasks were in the form of tabulated numbers defining criteria that evaluated the level of realization of the assumed targets in different technological variants. 
Table 2 Assessment of technological quality of two variants of STPP production

\begin{tabular}{|c|c|c|c|c|}
\hline \multirow[t]{2}{*}{ Group of criteria } & \multirow[t]{2}{*}{ Criteria symbol } & \multirow[t]{2}{*}{ Criteria of assessment of STPP processes } & \multicolumn{2}{|c|}{$\begin{array}{l}\text { Scoring of tripolyphosphate } \\
\text { production variants (points) }\end{array}$} \\
\hline & & & $\begin{array}{l}\text { Classic } \\
\text { method } \\
(\mathrm{CM})\end{array}$ & $\begin{array}{l}\text { Dry single-stage } \\
\text { method (DSM) }\end{array}$ \\
\hline \multirow{10}{*}{$\begin{array}{l}\text { Technical level } W_{1} \\
\text { Degree of validity } \\
a_{1}=1\end{array}$} & $\mathrm{~T} 1$ & Probability of success & 3 & 3 \\
\hline & $\mathrm{T} 2$ & Implementation period & 2 & 3 \\
\hline & $\mathrm{T} 3$ & Degree of novelty & 2 & 3 \\
\hline & $\mathrm{T} 4$ & Process simplification & 1.5 & 3 \\
\hline & T5 & Difficulty level & 2 & 3 \\
\hline & T6 & $\begin{array}{l}\text { Reduction in number of operations and unit } \\
\text { processes }\end{array}$ & 1.5 & 3 \\
\hline & $\mathrm{T} 7$ & Improvement of product quality & 3 & 3 \\
\hline & $\mathrm{T} 8$ & $\begin{array}{l}\text { Reduction in the number of production stages } \\
\text { and shortening of transportation routes }\end{array}$ & 1 & 3 \\
\hline & T9 & Repair and maintenance costs & 1.5 & 3 \\
\hline & $\mathrm{T} 10$ & Easier process & 1.5 & 3 \\
\hline \multicolumn{3}{|l|}{ Total assessment of $W_{1}$ group } & 19 & 30 \\
\hline \multicolumn{3}{|c|}{ Assessment of technical level taking into account degree of validity $a_{1} \cdot W_{1}$} & 19 & 30 \\
\hline \multirow{9}{*}{$\begin{array}{l}\text { Environmental } W_{2} \\
\text { Degree of validity } \\
a_{2}=3\end{array}$} & E1 & $\begin{array}{l}\text { Changes and modifications of technological } \\
\text { solutions }\end{array}$ & 1.5 & 3 \\
\hline & E2 & Changes of project solutions & 1.5 & 3 \\
\hline & E3 & Machinery changes in process & 1.5 & 3 \\
\hline & E4 & Changes in process manuals & 1 & 3 \\
\hline & E5 & In-process recycling of energy & 3 & 3 \\
\hline & E6 & Dust emission prevention & 2.5 & 3 \\
\hline & E7 & Reduction in energy consumption & 1 & 3 \\
\hline & E8 & Reduction in pollution emission & 2 & 3 \\
\hline & E9 & $\begin{array}{l}\text { Coefficients of cumulated hazard related to } \\
\text { release of waste into environment }\end{array}$ & 2 & 3 \\
\hline \multicolumn{3}{|l|}{ Total assessment of $W_{2}$ group } & 16 & 27 \\
\hline \multicolumn{3}{|c|}{ Environmental assessment taking into account degree of validity $a_{2} \cdot W_{2}$} & 48 & 81 \\
\hline \multirow{6}{*}{$\begin{array}{l}\text { Economic } W_{3} \\
\text { Degree of validity } \\
a_{3}=2\end{array}$} & F1 & Labor demand & 2 & 2 \\
\hline & $\mathrm{F} 2$ & Cumulative energy & 1.5 & 3 \\
\hline & F3 & Cumulated material consumption & 2 & 2 \\
\hline & F4 & Process costs & 2.5 & 3 \\
\hline & F5 & Investment level & 1 & 3 \\
\hline & F6 & Amortization & 1.5 & 3 \\
\hline \multicolumn{3}{|l|}{ Total assessment of $W_{3}$ group } & 10.5 & 16 \\
\hline \multicolumn{3}{|c|}{ Economic assessment taking into account degree of validity $a_{3} \cdot W_{3}$} & 21 & 32 \\
\hline \multicolumn{3}{|c|}{ Final assessment of technological quality $Q_{\text {mean }}=\left(a_{1} \cdot W_{1}+a_{2} \cdot W_{2}+a_{3} \cdot W_{3}\right) / 3$} & 29.33 & 47.67 \\
\hline
\end{tabular}

The next essential step was a choice of the type of multicriteria analysis method. Three methods of multi-criteria analysis have been applied (Generowicz et al. 2011a, b; Govindan et al. 2015; Gaska et al. 2017): the Borda method, the method of compromise programming, and the analytical hierarchy process (AHP).

The Borda method orders positions of the strategies separately according to a consecutive criterion of assessment and then aggregates partial ratings into a final ordering, enabling a choice of the best strategy. This method exploits the principle of aggregating partial strategy positions into final ordering with regard to all criteria:

$$
D_{n}=\sum_{m=1}^{M} D_{n m}
$$


where $D_{n m}$ is the position of the strategy $s_{n}$ in order according to the criterion $r_{m}$, and $D_{n}$ is the summary position of strategies based on all criteria.

Ordering of strategies $\mathrm{s}_{\mathrm{i}}$ from the most to the least advantageous is established according to increasing values of $D_{n}$ :

$s_{i} \rightarrow s_{j} \Leftrightarrow D_{i}<D_{j} ; \quad i, j=1, \ldots, N$

The most advantageous strategy $s^{*}$ is defined as

$s^{*}=s_{j} \Leftrightarrow D_{j}=\min \left\{D_{n}\right\} ; \quad n=1, \ldots, N$

where $s_{j}, D_{j}$, and $D_{n}$ are "summary" positions of strategies based on all criteria, $n=1, \ldots, N$.

The method of compromise programming orders positions of the individual strategies according to the distance of the strategy from a predetermined ideal point representing the most favorable solution. This method is based on the idea of ordering the individual strategies according to their distance from the fixed ideal points $x^{\prime}\left(x_{1}{ }^{\prime}, x_{2}{ }^{\prime}, \ldots, x_{\mathrm{M}}{ }^{\prime}\right)$, all coordinates of which characterize the most beneficial value on the basis of the same criteria. The criterion aggregating a measure of the distance of the investigated strategy from the ideal point has the form:

$L_{\alpha}\left(s_{n}\right)=\sum_{m=1}^{M} W_{m}^{\alpha} \cdot\left(x_{m}^{\prime}-r_{N M}^{\prime}\right)^{\alpha}$

The choice of the best strategy $s^{*}$ is made according to the principle:

$s^{*}=s_{j} \Leftrightarrow L_{\alpha}\left(s_{j}\right)=\min L_{\alpha}\left(s_{n}\right) ; \quad n=1,2, \ldots, N$

where $L_{\alpha}\left(s_{n}\right)$ is the distance of the examined strategy $s_{n}$ from the ideal point, $s^{*}$ the strategy chosen, $\mathrm{w}_{\mathrm{m}}$ the coefficient of the criterion $m, x_{m}{ }^{\prime}$ the coordinate of the utopian point $m, r_{N M}{ }^{\prime}$ the normalized value of the criterion, $M$ the number of criteria, and $\alpha$ the exponent indicating deviation of the strategy from the utopian point $x^{\prime}$ (in practice, it is assumed to be 1,2 or $\infty$ ).

The application of the above multi-criteria analysis method, while additionally taking into account "weighting" criteria, gives a final solution of the decision task. The final result is in the form of ranking/ordering of the variants of the analyzed technology of STPP production from the most to the least advantageous solution.

AHP (analytical hierarchy method) is a method in which preferences are evaluated using relative values based on significances of the criteria assessing the variants. Assessments arise from pair-wise comparisons of all the criteria on a certain hierarchical level.

The analytical hierarchy process (Saaty 2001; Zopounidis and Doumpos 2002) enables the achievement ranking of many acceptable variant projects with regard to many nonequivalent criteria of the assessment. The final assessment is performed taking into account all criteria simultaneously. To facilitate calculations and comparisons, the hierarchical representation is often arranged as a "value/decision tree" built of all the variants and criteria.
A problem of the method is with testing coherence of the preferences of matrices. For this purpose, Saaty (1980) proposed calculation of two coherence coefficients: CI (consistency index) and CR (consistency ratio). The preference of the matrix $A$ is defined by the formula

$A=\left(a_{i j}\right)_{i, j=1, \ldots, n}$

where $n$ is the number of objects and $\mathrm{a}_{\mathrm{ij}}$ an element of the matrix.

The matrix is treated as sufficiently coherent when the value of the coefficient CR is lower than 0.1. Coherence coefficients guarantee that the matrix constructed by pair-wise comparisons does not contain contradictions or inconsistencies. Elements of the matrix $a_{i j}$ are defined as a degree of the preference of the object $(i)$ over $(j)$ in the 9-point Saaty scale. The more preference given to object $(i)$ over object $(j)$, the higher the value assigned to the element $a_{i j}$. The result of object comparisons makes all ratios of relative weightings of those objects for the assessment in question simultaneously, therefore

$a_{i j}=\omega_{i} / \omega_{j}$

where $\omega$ is the preferences, while particular matrix elements (criteria for variant assessment) are compared.

The final assessment is performed with respect to all criteria simultaneously and requires determination of the aggregation rule $(H)$, in other words, assessment of variants with regard to all criteria simultaneously. The variant with the highest number of the $H$ function is the best (including all criteria jointly) and, as such, has the highest degree of usefulness for the decision. In practice, the most frequently used aggregation formula is as follows (Georgopoulou et al. 2008; Govindan et al. 2015):

$H\left(W_{i}\right)=\sum_{j} \omega_{j} \cdot K_{j}\left(W_{i}\right)$

where $H$ is the formula of criteria aggregation (in a form to evaluate variants by all criteria simultaneously), $\mathrm{W}_{\mathrm{i}}$ the decision variant with index $(i), K_{j}$ the criterion with index $(j)$, $\omega_{j}$ the relative weight of criterion $K_{j}$, and $K_{j}\left(W_{i}\right)$ the partial assessment of the $W_{i}$ variant on $K_{j}$ criterion.

\section{Results and discussion}

\section{Results of multi-criteria analysis for the choice of technological variants of tripolyphosphate production between classic-spray and dry, single-stage methods}

Multi-criteria analysis using an assessment of particular BATNEEC options and indices for complex quality assessment as criteria of STPP production makes it possible to 
write a decision matrix for the choice of technology according to the following decision methods: Borda, compromise programming, and AHP.

\section{Results of multi-criteria analysis of the variants of STPP production obtained by Borda and compromise programming methods}

The Borda method is the simplest one and gives a unique solution dependent only on criteria, and is not dependent on the preferences of a decision-maker. The method of compromise programming gives more complex results, as there is a possibility for "weighting" assignments for particular criteria. For application of the compromise programming method, it is necessary to make a hierarchy of the validity of the particular criteria, determining the priority of the participants in the decision process. At the beginning, ordering obtained with regard to the same "weightings" for all criteria are examined. Next, after a reasonable change in "weightings," ordering is examined to find out whether there is a change, particularly at the beginning of the rank. If orderings so obtained are resistant to "weighting" changes, it can be assumed that preferences of the decision-making person will not affect the choice of variant. In the adverse case, it is necessary to engage the decision-maker in the decision process and make further investigations into their preferences.

The results and final ranking of particular variants based on Borda and compromise programming with the use of assessment indices of BATNEEC options are presented in Table 3. In ordering with respect to compromise programming, solutions depending on the value of "weightings" assigned for individual criterion have been presented. In the last six rows (Table 3), the method of "weightings" assignment was additionally differentiated. The "weightings" were assigned for all the groups of criteria according to technical, economic, and environmental aspects. In the last row, "weightings" of criteria that had the same value in the assessment of two analyzed technologies were increased. That resulted from small differences in the description and the values of criteria differentiating the technologies.

As a result, a ranking of technological variants of STPP production from the most to the least advantageous solution was obtained. The method makes it possible to get an additional "weighting" of the criteria by applying an exponent $\alpha$. The exponent allows for the additional "weighting" of each deviation from the ideal point in proportion to its magnitude. The higher $\alpha$ value, the higher the significance of the deviation of the strategy is from the ideal point. Individual cases based on different $\alpha$ values are presented in Tables 3 and 4 .

In all cases (which is not typical), the technology of STPP production chosen as the most advantageous was dry singlestage technology (DSM), although, according to the BATNEEC assessment, classic and dry single-stage technologies were very close. In correspondence with that, in some calculated cases, the positions of the classic technology as well as those of dry single-stage method were very close to the utopian point. Those cases, characterized by close or identical values of both technological solutions, appeared after the value of the $\alpha$ coefficient was increased and "weighting" criteria were increased from 1 to 5 . Nevertheless, it can be explicitly concluded that the most advantageous variant, according to both multi-criteria analyses, is the dry singlestage technology of STPP production.

Results and final rankings of particular variants based on Borda and compromise programming with the use of indices of complex quality assessment as criteria are presented in Table 4. Calculated results of the complex quality assessment of the technological solutions taken from Table 2 constituted the decision matrix for multi-criteria analysis. Application of Borda and compromise programming methods allowed for ordering the variants of STPP production, from the most to the least advantageous technological solution. In these calculations and analyses, assumptions similar to the BATNEEC options were made. Ordering was examined by changing "weightings" of individual criteria and groups of criteria (end of Table 4). Also, $\alpha$ coefficient was changed between 1,2 , and 5 .

The Borda method gave an explicitly unmistakable solution, similar to the BATNEEC options applied above. The most advantageous appeared to be the dry single-stage technology. The result obtained by the Borda method did not depend on preferences of a decision-making person. Meanwhile, the compromise programming method gave a more complex outcome, as there was a possibility of different "weighting" assignments to separate criteria. In all cases, similar to the above, the most advantageous technology chosen was the dry single-stage one.

It has to be admitted that both technological solutions had similar assessments in the ranking, and differences in the technology assessments were small. In the section above, where the BATNEEC criteria were scored using a 10-point scale, the differences in the assessment of the technologies were more expressed; consequently, it was possible to isolate nearby solutions and reach firm ground to claim that both technological solutions acquired similar assessments. A difference of one point in the assessment gave a very high difference in multi-criteria analysis. In conclusion, ranking of the technological solutions indicated that the dry singlestage method of STPP production was the advantageous technological variant.

\section{Results of multi-criteria analysis of the variants of STPP production made with the AHP method}

The third method applied was AHP, with the use of the HIPRE program (Hämäläinen and Kettunen 1994; Salo and 
Table 3 Ranking of the technological variants of STPP production, based on Borda and compromise programming methods with the use of assessment indices of BATNEEC options indicated in Table 1

\begin{tabular}{|c|c|c|c|c|}
\hline \multirow{4}{*}{$\begin{array}{l}\text { Multi-criteria method } \\
\text { Borda } \\
\text { Compromise programming }\end{array}$} & \multicolumn{4}{|l|}{ Calculation results } \\
\hline & \multirow{3}{*}{$\begin{array}{l}\text { Hierarchy in criteria validity in assessment using BATNEEC options SD1: } \\
\text { SD2:SD3:SD4:SD5:SD6:SD7:SD8:SD9:IE1:IE2:IE3:IE4:Ec1:Ec2:Ec3:Ec } \\
\text { 4:Ec5:Ec6:Ec7:Ec8 }\end{array}$} & \multicolumn{3}{|l|}{$\mathrm{DSM}>\mathrm{CM}$} \\
\hline & & \multicolumn{3}{|c|}{$\begin{array}{l}\text { Ranking of variants depending on } \\
\text { hierarchy of criteria validity and } \alpha \\
\text { assigned }\end{array}$} \\
\hline & & $\alpha=1$ & $\alpha=2$ & $\alpha=5$ \\
\hline & 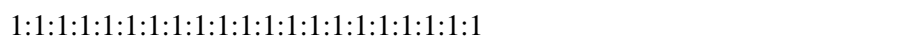 & $\mathrm{DSM}>\mathrm{CM}$ & $\mathrm{DSM}>\mathrm{CM}$ & $\mathrm{DSM}>\mathrm{CM}$ \\
\hline & $5: 1: 1: 1: 1: 1: 1: 1: 1: 1: 1: 1: 1: 1: 1: 1: 1: 1: 1: 1: 1$ & $\mathrm{DSM}>\mathrm{CM}$ & $\mathrm{DSM}>\mathrm{CM}$ & $\mathrm{DSM}>\mathrm{CM}$ \\
\hline & 1:5:1:1:1:1:1:1:1:1:1:1:1:1:1:1:1:1:1:1:1 & $\mathrm{DSM}>\mathrm{CM}$ & $\mathrm{DSM}>\mathrm{CM}$ & $\mathrm{DSM}>\mathrm{CM}$ \\
\hline & 1:1:5:1:1:1:1:1:1:1:1:1:1:1:1:1:1:1:1:1:1 & $\mathrm{DSM}>\mathrm{CM}$ & $\mathrm{DSM}>\mathrm{CM}$ & $\mathrm{DSM}>\mathrm{CM}$ \\
\hline & 1:1:1:5:1:1:1:1:1:1:1:1:1:1:1:1:1:1:1:1:1 & $\mathrm{DSM}>\mathrm{CM}$ & $\mathrm{DSM}>\mathrm{CM}$ & $\mathrm{DSM}>\mathrm{CM}$ \\
\hline & 1:1:1:1:5:1:1:1:1:1:1:1:1:1:1:1:1:1:1:1:1 & $\mathrm{DSM}>\mathrm{CM}$ & $\mathrm{DSM}>\mathrm{CM}$ & $\mathrm{DSM}>\mathrm{CM}$ \\
\hline & 1:1:1:1:1:5:1:1:1:1:1:1:1:1:1:1:1:1:1:1:1 & $\mathrm{DSM}>\mathrm{CM}$ & $\mathrm{DSM}>\mathrm{CM}$ & $\mathrm{DSM}>\mathrm{CM}$ \\
\hline & $1: 1: 1: 1: 1: 1: 5: 1: 1: 1: 1: 1: 1: 1: 1: 1: 1: 1: 1: 1: 1$ & $\mathrm{DSM}>\mathrm{CM}$ & $\mathrm{DSM}>\mathrm{CM}$ & $\mathrm{DSM}>\mathrm{CM}$ \\
\hline & 1:1:1:1:1:1:1:5:1:1:1:1:1:1:1:1:1:1:1:1:1 & $\mathrm{DSM}>\mathrm{CM}$ & $\mathrm{DSM}>\mathrm{CM}$ & $\mathrm{DSM}>\mathrm{CM}$ \\
\hline & 1:1:1:1:1:1:1:1:5:1:1:1:1:1:1:1:1:1:1:1:1 & $\mathrm{DSM}>\mathrm{CM}$ & $\mathrm{DSM}>\mathrm{CM}$ & $\mathrm{DSM}>\mathrm{CM}$ \\
\hline & 1:1:1:1:1:1:1:1:1:5:1:1:1:1:1:1:1:1:1:1:1 & $\mathrm{DSM}>\mathrm{CM}$ & $\mathrm{DSM}>\mathrm{CM}$ & $\mathrm{DSM}>\mathrm{CM}$ \\
\hline & 1:1:1:1:1:1:1:1:1:1:5:1:1:1:1:1:1:1:1:1:1 & $\mathrm{DSM}>\mathrm{CM}$ & $\mathrm{DSM}>\mathrm{CM}$ & $\mathrm{DSM}>\mathrm{CM}$ \\
\hline & 1:1:1:1:1:1:1:1:1:1:1:5:1:1:1:1:1:1:1:1:1 & $\mathrm{DSM}>\mathrm{CM}$ & $\mathrm{DSM}>\mathrm{CM}$ & $\mathrm{DSM}>\mathrm{CM}$ \\
\hline & 1:1:1:1:1:1:1:1:1:1:1:1:5:1:1:1:1:1:1:1:1 & $\mathrm{DSM}>\mathrm{CM}$ & $\mathrm{DSM}>\mathrm{CM}$ & $\mathrm{DSM}>\mathrm{CM}$ \\
\hline & 1:1:1:1:1:1:1:1:1:1:1:1:1:5:1:1:1:1:1:1:1 & $\mathrm{DSM}>\mathrm{CM}$ & $\mathrm{DSM}>\mathrm{CM}$ & $\mathrm{DSM}>\mathrm{CM}$ \\
\hline & 1:1:1:1:1:1:1:1:1:1:1:1:1:1:5:1:1:1:1:1:1 & $\mathrm{DSM}>\mathrm{CM}$ & $\mathrm{DSM}>\mathrm{CM}$ & $\mathrm{DSM}>\mathrm{CM}$ \\
\hline & 1:1:1:1:1:1:1:1:1:1:1:1:1:1:1:5:1:1:1:1:1 & $\mathrm{DSM}>\mathrm{CM}$ & $\mathrm{DSM}>\mathrm{CM}$ & $\mathrm{DSM}>\mathrm{CM}$ \\
\hline & 1:1:1:1:1:1:1:1:1:1:1:1:1:1:1:1:5:1:1:1:1 & $\mathrm{DSM}>\mathrm{CM}$ & $\mathrm{DSM}>\mathrm{CM}$ & $\mathrm{DSM}>\mathrm{CM}$ \\
\hline & 1:1:1:1:1:1:1:1:1:1:1:1:1:1:1:1:1:5:1:1:1 & $\mathrm{DSM}>\mathrm{CM}$ & $\mathrm{DSM}>\mathrm{CM}$ & $\mathrm{DSM}>\mathrm{CM}$ \\
\hline & 1:1:1:1:1:1:1:1:1:1:1:1:1:1:1:1:1:1:5:1:1 & $\mathrm{DSM}>\mathrm{CM}$ & $\mathrm{DSM}>\mathrm{CM}$ & $\mathrm{DSM}>\mathrm{CM}$ \\
\hline & 1:1:1:1:1:1:1:1:1:1:1:1:1:1:1:1:1:1:1:5:1 & $\mathrm{DSM}>\mathrm{CM}$ & $\mathrm{DSM}>\mathrm{CM}$ & $\mathrm{DSM}>\mathrm{CM}$ \\
\hline & 1:1:1:1:1:1:1:1:1:1:1:1:1:1:1:1:1:1:1:1:5 & $\mathrm{DSM}>\mathrm{CM}$ & $\mathrm{DSM}>\mathrm{CM}$ & $\mathrm{DSM}>\mathrm{CM}$ \\
\hline & 1:5:1:1:1:5:1:5:1:1:1:5:5:5:1:5:1:5:5:5:1 & $\mathrm{DSM}>\mathrm{CM}$ & $\mathrm{DSM}>\mathrm{CM}$ & $\mathrm{DSM}>\mathrm{CM}$ \\
\hline & $\begin{array}{l}\text { Hierarchy in criteria validity in the groups of criteria assessing BATNEEC } \\
\text { options SD1-SD9:IE1-IE4:Ec1-Ec8 }\end{array}$ & $\alpha=1$ & $\alpha=2$ & $\alpha=5$ \\
\hline & $5: 1: 1$ & $\mathrm{DSM}>\mathrm{CM}$ & $\mathrm{DSM}>\mathrm{CM}$ & $\mathrm{DSM}>\mathrm{CM}$ \\
\hline & $1: 5: 1$ & $\mathrm{DSM}>\mathrm{CM}$ & $\mathrm{DSM}>\mathrm{CM}$ & $\mathrm{DSM}>\mathrm{CM}$ \\
\hline & $1: 1: 5$ & $\mathrm{DSM}>\mathrm{CM}$ & $\mathrm{DSM}>\mathrm{CM}$ & $\mathrm{DSM}>\mathrm{CM}$ \\
\hline & $5: 1: 5$ & $\mathrm{DSM}>\mathrm{CM}$ & $\mathrm{DSM}>\mathrm{CM}$ & $\mathrm{DSM}>\mathrm{CM}$ \\
\hline & $5: 5: 1$ & $\mathrm{DSM}>\mathrm{CM}$ & $\mathrm{DSM}>\mathrm{CM}$ & $\mathrm{DSM}>\mathrm{CM}$ \\
\hline & $1: 5: 5$ & $\mathrm{DSM}>\mathrm{CM}$ & $\mathrm{DSM}>\mathrm{CM}$ & $\mathrm{DSM}>\mathrm{CM}$ \\
\hline
\end{tabular}

Hämäläinen 1995). Figure 2 illustrates "a hierarchical value tree" built up of variants of technology and assessment criteria for STPP production (Saaty 2001; Larrodé et al. 2012).

In the proposed AHP method, there was a possibility to assign "weightings" for each group of criteria and for criterion by themselves. In the example presented below, groups of criteria underwent, in turn, outweighing. Figure $3 \mathrm{a}-\mathrm{c}$ demonstrates results of multi-criteria analysis (AHP) after significant outweighings of technical, environmental, and economic criteria, respectively. Figure 3 a presents the result of calculations where the "weightings" of technical, economic, and environmental criteria were $0.788,0.046$, and 0.165 , respectively. Figure $3 \mathrm{~b}$ illustrates the result of calculations after economic criteria were outweighed and the ratio of "weightings" amounted to 0.042, 0.778, and 0.18, while Fig. 3c presents results of ordering variants for "weightings" of $0.097,0.086$, and 0.818 . In each of the analyzed cases, the dry single-stage method was again chosen as more advantageous than the classic method of STPP production.

Figure $3 \mathrm{a}-\mathrm{c}$ demonstrates that a predominance of the environmental "weighting" criterion gave a higher result for the dry single-stage method. Also, a predominance of 
Table 4 Ranking of technological variants of STPP production, based on Borda and compromise programming methods using indices for complex quality assessment from Table 2

\begin{tabular}{|c|c|c|c|c|}
\hline \multirow{4}{*}{$\begin{array}{l}\text { Multi-criteria method } \\
\text { Borda } \\
\text { Compromise programming }\end{array}$} & \multicolumn{4}{|l|}{ Calculation results } \\
\hline & \multirow{3}{*}{$\begin{array}{l}\text { Hierarchy in criteria validity for assessment of complex quality T1:T2:T3 } \\
\text { :T4:T5:T6:T7:T8:T9:T10:E1:E2:E3:E4:E5:E6:E7:E8:E9:F1:F2:F3:F4:F } \\
\text { 5:F6 }\end{array}$} & \multicolumn{3}{|l|}{$\mathrm{DSM}>\mathrm{CM}$} \\
\hline & & \multicolumn{3}{|c|}{$\begin{array}{l}\text { Ranking of variants depending on } \\
\text { hierarchy of criteria validity and } \alpha \\
\text { assigned }\end{array}$} \\
\hline & & $\alpha=1$ & $\alpha=2$ & $\alpha=5$ \\
\hline & 1:1:1:1:1:1:1:1:1:1:1:1:1:1:1:1:1:1:1:1:1:1:1:1:1 & $\mathrm{DSM}>\mathrm{CM}$ & $\mathrm{DSM}>\mathrm{CM}$ & $\mathrm{DSM}>\mathrm{CM}$ \\
\hline & 5:1:1:1:1:1:1:1:1:1:1:1:1:1:1:1:1:1:1:1:1:1:1:1:1 & $\mathrm{DSM}>\mathrm{CM}$ & $\mathrm{DSM}>\mathrm{CM}$ & $\mathrm{DSM}>\mathrm{CM}$ \\
\hline & 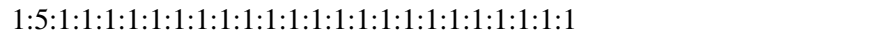 & $\mathrm{DSM}>\mathrm{CM}$ & $\mathrm{DSM}>\mathrm{CM}$ & $\mathrm{DSM}>\mathrm{CM}$ \\
\hline & 1:1:5:1:1:1:1:1:1:1:1:1:1:1:1:1:1:1:1:1:1:1:1:1:1 & $\mathrm{DSM}>\mathrm{CM}$ & $\mathrm{DSM}>\mathrm{CM}$ & $\mathrm{DSM}>\mathrm{CM}$ \\
\hline & 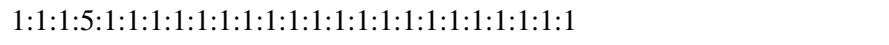 & $\mathrm{DSM}>\mathrm{CM}$ & $\mathrm{DSM}>\mathrm{CM}$ & $\mathrm{DSM}>\mathrm{CM}$ \\
\hline & 1:1:1:1:5:1:1:1:1:1:1:1:1:1:1:1:1:1:1:1:1:1:1:1:1 & $\mathrm{DSM}>\mathrm{CM}$ & $\mathrm{DSM}>\mathrm{CM}$ & $\mathrm{DSM}>\mathrm{CM}$ \\
\hline & $1: 1: 1: 1: 1: 5: 1: 1: 1: 1: 1: 1: 1: 1: 1: 1: 1: 1: 1: 1: 1: 1: 1: 1: 1$ & $\mathrm{DSM}>\mathrm{CM}$ & $\mathrm{DSM}>\mathrm{CM}$ & $\mathrm{DSM}>\mathrm{CM}$ \\
\hline & $1: 1: 1: 1: 1: 1: 5: 1: 1: 1: 1: 1: 1: 1: 1: 1: 1: 1: 1: 1: 1: 1: 1: 1: 1$ & $\mathrm{DSM}>\mathrm{CM}$ & $\mathrm{DSM}>\mathrm{CM}$ & $\mathrm{DSM}>\mathrm{CM}$ \\
\hline & 1:1:1:1:1:1:1:5:1:1:1:1:1:1:1:1:1:1:1:1:1:1:1:1:1 & $\mathrm{DSM}>\mathrm{CM}$ & $\mathrm{DSM}>\mathrm{CM}$ & $\mathrm{DSM}>\mathrm{CM}$ \\
\hline & 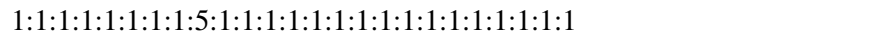 & $\mathrm{DSM}>\mathrm{CM}$ & $\mathrm{DSM}>\mathrm{CM}$ & $\mathrm{DSM}>\mathrm{CM}$ \\
\hline & 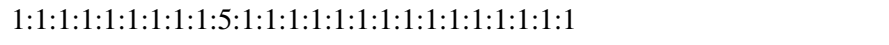 & $\mathrm{DSM}>\mathrm{CM}$ & $\mathrm{DSM}>\mathrm{CM}$ & $\mathrm{DSM}>\mathrm{CM}$ \\
\hline & 1:1:1:1:1:1:1:1:1:1:5:1:1:1:1:1:1:1:1:1:1:1:1:1:1 & $\mathrm{DSM}>\mathrm{CM}$ & $\mathrm{DSM}>\mathrm{CM}$ & $\mathrm{DSM}>\mathrm{CM}$ \\
\hline & 1:1:1:1:1:1:1:1:1:1:1:5:1:1:1:1:1:1:1:1:1:1:1:1:1 & $\mathrm{DSM}>\mathrm{CM}$ & $\mathrm{DSM}>\mathrm{CM}$ & $\mathrm{DSM}>\mathrm{CM}$ \\
\hline & $1: 1: 1: 1: 1: 1: 1: 1: 1: 1: 1: 1: 5: 1: 1: 1: 1: 1: 1: 1: 1: 1: 1: 1: 1$ & $\mathrm{DSM}>\mathrm{CM}$ & $\mathrm{DSM}>\mathrm{CM}$ & $\mathrm{DSM}>\mathrm{CM}$ \\
\hline & 1:1:1:1:1:1:1:1:1:1:1:1:1:5:1:1:1:1:1:1:1:1:1:1:1 & $\mathrm{DSM}>\mathrm{CM}$ & $\mathrm{DSM}>\mathrm{CM}$ & $\mathrm{DSM}>\mathrm{CM}$ \\
\hline & 1:1:1:1:1:1:1:1:1:1:1:1:1:1:5:1:1:1:1:1:1:1:1:1:1 & $\mathrm{DSM}>\mathrm{CM}$ & $\mathrm{DSM}>\mathrm{CM}$ & $\mathrm{DSM}>\mathrm{CM}$ \\
\hline & $1: 1: 1: 1: 1: 1: 1: 1: 1: 1: 1: 1: 1: 1: 1: 5: 1: 1: 1: 1: 1: 1: 1: 1: 1$ & $\mathrm{DSM}>\mathrm{CM}$ & $\mathrm{DSM}>\mathrm{CM}$ & $\mathrm{DSM}>\mathrm{CM}$ \\
\hline & $1: 1: 1: 1: 1: 1: 1: 1: 1: 1: 1: 1: 1: 1: 1: 1: 5: 1: 1: 1: 1: 1: 1: 1: 1$ & $\mathrm{DSM}>\mathrm{CM}$ & $\mathrm{DSM}>\mathrm{CM}$ & $\mathrm{DSM}>\mathrm{CM}$ \\
\hline & 1:1:1:1:1:1:1:1:1:1:1:1:1:1:1:1:1:5:1:1:1:1:1:1:1 & $\mathrm{DSM}>\mathrm{CM}$ & $\mathrm{DSM}>\mathrm{CM}$ & $\mathrm{DSM}>\mathrm{CM}$ \\
\hline & 1:1:1:1:1:1:1:1:1:1:1:1:1:1:1:1:1:1:5:1:1:1:1:1:1 & $\mathrm{DSM}>\mathrm{CM}$ & $\mathrm{DSM}>\mathrm{CM}$ & $\mathrm{DSM}>\mathrm{CM}$ \\
\hline & 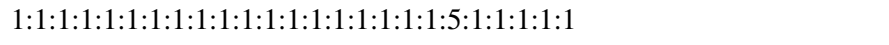 & $\mathrm{DSM}>\mathrm{CM}$ & $\mathrm{DSM}>\mathrm{CM}$ & $\mathrm{DSM}>\mathrm{CM}$ \\
\hline & 1:1:1:1:1:1:1:1:1:1:1:1:1:1:1:1:1:1:1:1:5:1:1:1:1 & $\mathrm{DSM}>\mathrm{CM}$ & $\mathrm{DSM}>\mathrm{CM}$ & $\mathrm{DSM}>\mathrm{CM}$ \\
\hline & 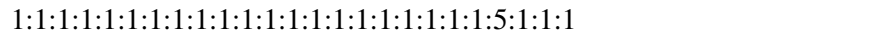 & $\mathrm{DSM}>\mathrm{CM}$ & $\mathrm{DSM}>\mathrm{CM}$ & $\mathrm{DSM}>\mathrm{CM}$ \\
\hline & 1:1:1:1:1:1:1:1:1:1:1:1:1:1:1:1:1:1:1:1:1:1:5:1:1 & $\mathrm{DSM}>\mathrm{CM}$ & $\mathrm{DSM}>\mathrm{CM}$ & $\mathrm{DSM}>\mathrm{CM}$ \\
\hline & 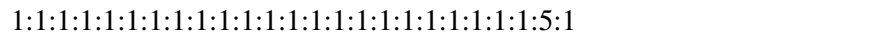 & $\mathrm{DSM}>\mathrm{CM}$ & $\mathrm{DSM}>\mathrm{CM}$ & $\mathrm{DSM}>\mathrm{CM}$ \\
\hline & 1:1:1:1:1:1:1:1:1:1:1:1:1:1:1:1:1:1:1:1:1:1:1:1:5 & $\mathrm{DSM}>\mathrm{CM}$ & $\mathrm{DSM}>\mathrm{CM}$ & $\mathrm{DSM}>\mathrm{CM}$ \\
\hline & $\begin{array}{l}\text { Hierarchy in criteria validity of the groups of complex quality assessment } \\
\text { T1-T10:E1-E9:F1-F6 }\end{array}$ & $\alpha=1$ & $\alpha=2$ & $\alpha=5$ \\
\hline & $5: 1: 1$ & $\mathrm{DSM}>\mathrm{CM}$ & $\mathrm{DSM}>\mathrm{CM}$ & $\mathrm{DSM}>\mathrm{CM}$ \\
\hline & $1: 5: 1$ & $\mathrm{DSM}>\mathrm{CM}$ & $\mathrm{DSM}>\mathrm{CM}$ & $\mathrm{DSM}>\mathrm{CM}$ \\
\hline & $1: 1: 5$ & $\mathrm{DSM}>\mathrm{CM}$ & $\mathrm{DSM}>\mathrm{CM}$ & $\mathrm{DSM}>\mathrm{CM}$ \\
\hline & $5: 5: 1$ & $\mathrm{DSM}>\mathrm{CM}$ & $\mathrm{DSM}>\mathrm{CM}$ & $\mathrm{DSM}>\mathrm{CM}$ \\
\hline & $1: 5: 5$ & $\mathrm{DSM}>\mathrm{CM}$ & $\mathrm{DSM}>\mathrm{CM}$ & $\mathrm{DSM}>\mathrm{CM}$ \\
\hline & $5: 1: 5$ & $\mathrm{DSM}>\mathrm{CM}$ & $\mathrm{DSM}>\mathrm{CM}$ & $\mathrm{DSM}>\mathrm{CM}$ \\
\hline
\end{tabular}

the technical or economic criterion gave a more profitable final result in the case of the dry single-stage method. However, the classic method gave very close results and ordering, particularly in the case of predominance of the technical criterion.

Application of the AHP method enables performance of sensitivity analysis by analyzing the result through a change in "weighting" of a selected criterion, while the "weightings" of the other criteria remain unchanged. Figure $4 \mathrm{a}-\mathrm{c}$ demonstrates an example of sensitivity analysis in the case where environmental criteria were significantly outweighed.

As can be seen in Fig. 4a, b, only a similar shift in "weightings" of technical and economic criteria from a very low number to about 0.9 could change the ordering sequence in a way that the classic method could be selected as more 


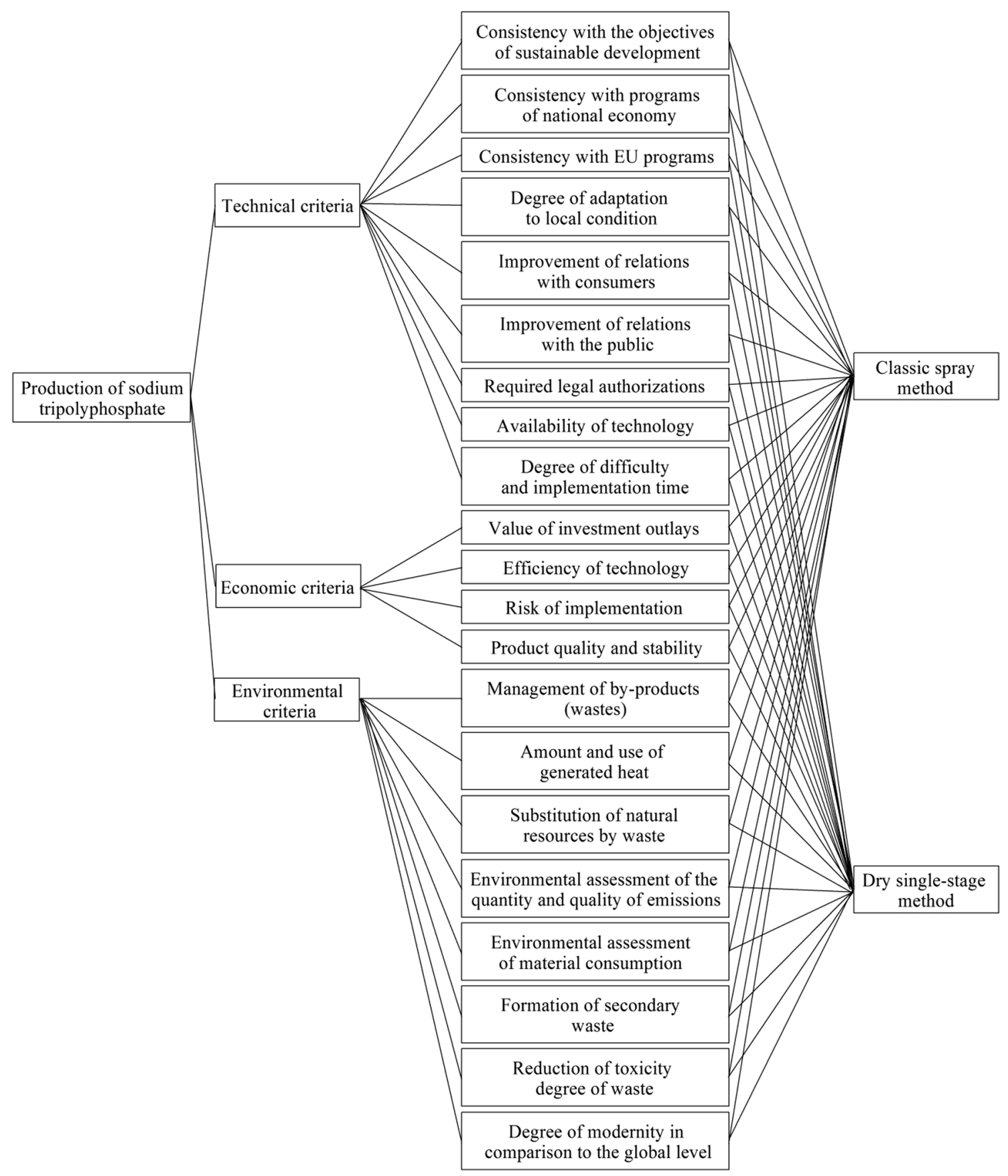

Fig. 2 Hierarchical tree built up of objectives for the choice of variants of STPP production with the AHP method

advantageous than the dry single-stage method. Meanwhile, in the case of the environmental criteria group, a shift of the "weighting" values toward very low ones (about 0.2 ) could change solutions and ordering.

Figure 5a, b illustrates results of multi-criteria analysis (AHP) after significant outweighing of the "weightings" in groups of criteria. These were assigned to the technical and economic criteria groups simultaneously (Fig. 5a) and to environmental criteria separately (Fig. 5b).
In all those cases, the dry single-stage method was chosen as significantly more advantageous than the classic method of STPP production. Results of AHP analysis are presented in Table 5.

The results obtained by the AHP method, specified in Table 4, confirm the conclusions from the Borda and compromise programming methods. From the figures, it can also be concluded that values of the assessment were not changing. 
Fig. 3 Results of AHP analysis and of criteria assessing BATNEEC options for choice of STPP technological variants considering predominance of "weightings" of the a technical, b economic, or c environmental criteria

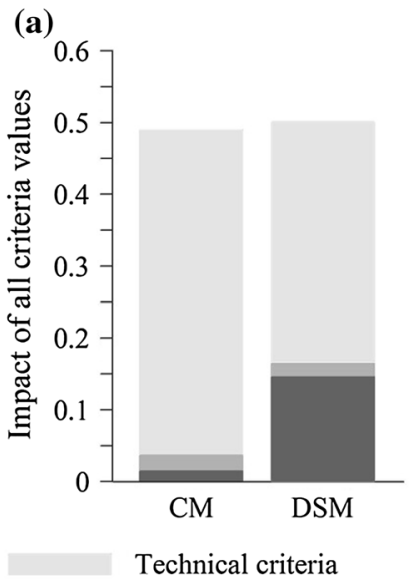

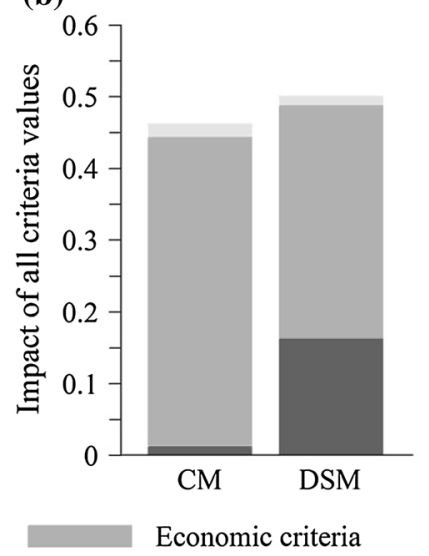

(c)

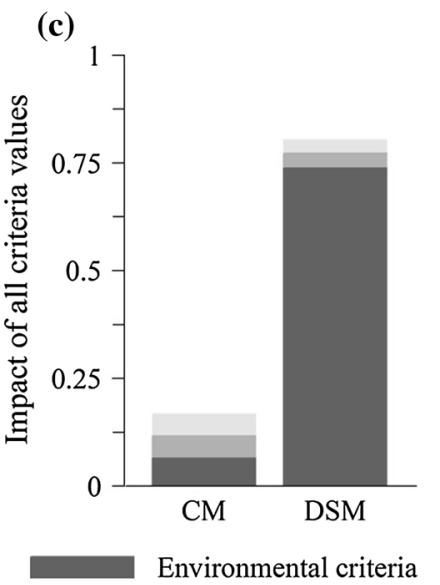

(a)

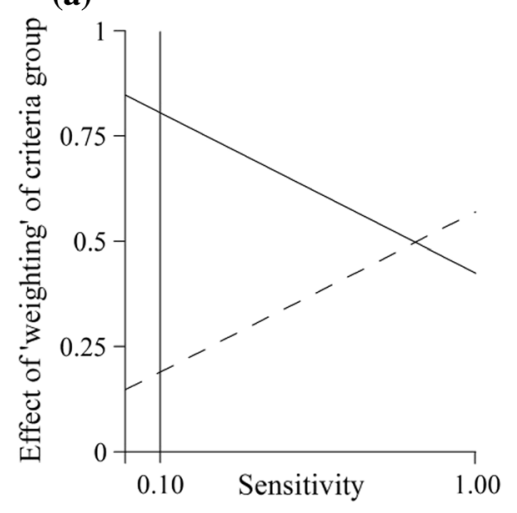

(b)

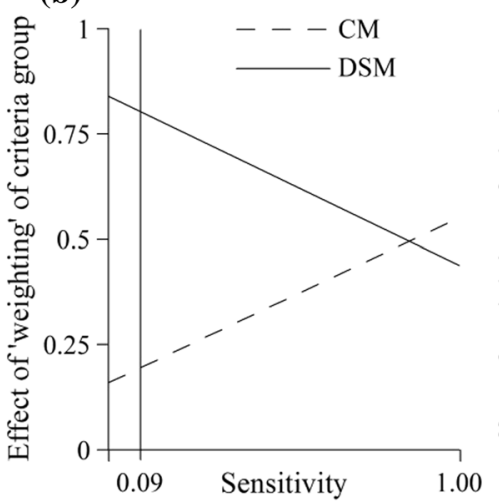

(c)

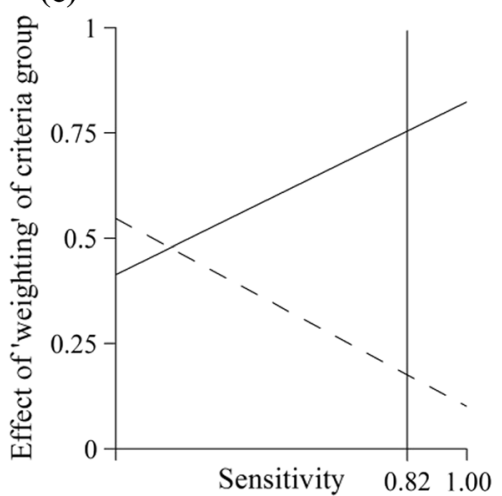

Fig. 4 Sensitivity analysis of the effect of "weighting" of a technical, b economic, and c environmental criteria groups on the choice of STPP production variant

(a)

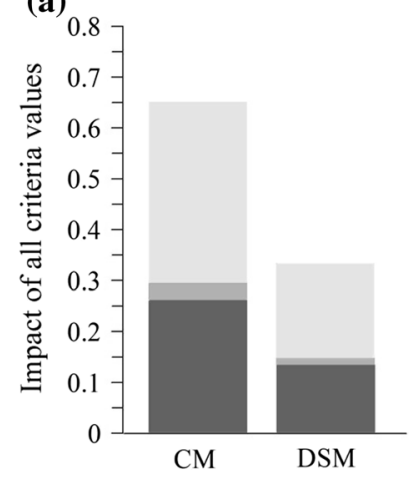

(b)

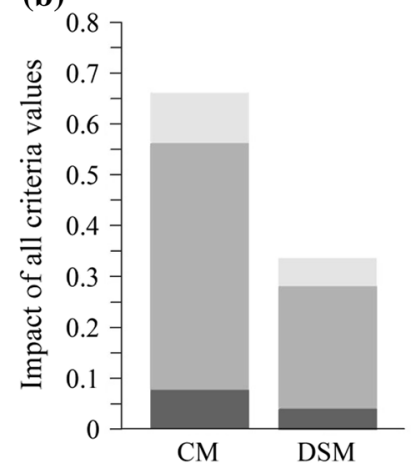

Environmental assessment

Evaluation of the technical level criteria

Fig. 5 Results of AHP analysis and of criteria assessing complex quality for choice of STPP technological variants while criteria were outweighed: a technical and economic criteria b environmental criteria
The only changes that could be observed were changes in relationships between "weightings" of criteria groups.

Sensitivity analysis performed with the use of the HIPRE program confirmed the results of multi-criteria analysis. With indices of technological quality setup, the ranking of technological variants of STPP production did not change depending on the hierarchy of criteria validity. Results obtained from AHP analysis confirmed the results obtained with the use of Borda and compromise programming methods.

\section{Conclusion}

Multi-criteria analysis allowed for choosing the dry singlestage method of STPP production as the most advantageous technology variant. Multi-criteria analysis using an assessment of particular BATNEEC options and indices for 
Table 5 Ranking of the technological variants of STPP production by classic and dry single-stage technology with the AHP method

\begin{tabular}{lll}
\hline No. & $\begin{array}{l}\text { "Weightings" assigned for the groups of } \\
\text { criteria: technical, economic, environmen- } \\
\text { tal }\end{array}$ & $\begin{array}{l}\text { Ranking of STPP } \\
\text { production variants } \\
\text { using }\end{array}$ \\
\hline Criteria assessing BATNEEC options & & \\
1 & $0.788,0.046,0.165$ & DSM $>$ CM \\
2 & $0.042,0.778,0.18$ & DSM $>$ CM \\
3 & $0.097,0.086,0.818$ & DSM $>C M$ \\
Criteria assessing indices of complex quality evaluation & \\
4 & $0.55,0.054,0.396$ & DSM $>C M$ \\
5 & $0.204,0.668,0.128$ & DSM $>C M$ \\
\hline
\end{tabular}

complex quality assessment as criteria of STPP production made it possible to write a decision matrix for the choice of technology according to the following decision methods: Borda, compromise programming, and analytical hierarch process (AHP). The use of various criteria types (BATNEEC options and indices for complex quality assessment) as evaluation criteria in multi-criteria analysis allowed for an independent evaluation of the technology. Calculations from Borda and compromise programming methods showed that, in all cases, the assessment criteria used reached the highest possible level for dry single-stage technology (DSM) for STPP production.

The classic technology (CM) of STPP production was not indicated by any assessment method as the superior choice. Results obtained by AHP method confirmed the conclusions from Borda and compromise programming methods.

It has to be admitted that both technological solutions gave similar assessments in the ranking, and differences in the technology assessments were low. In conclusion, ranking of the worked out technological solutions indicated the dry single-stage method of STPP production as the advantageous technological variant.

Acknowledgements This work was supported by the National Science Centre Poland (Grant Number N N209 088840).

Open Access This article is distributed under the terms of the Creative Commons Attribution 4.0 International License (http://creativeco mmons.org/licenses/by/4.0/), which permits unrestricted use, distribution, and reproduction in any medium, provided you give appropriate credit to the original author(s) and the source, provide a link to the Creative Commons license, and indicate if changes were made.

\section{References}

Aksu Mİ, Alp E (2012) Effects of sodium tripolyphosphate and modified atmosphere packaging on the quality characteristics and storage stability of ground beef. Food Technol Biotech 50:81-87

Gaska K, Generowicz A (2017) Advanced computational methods in component-oriented modelling of municipal solid waste incineration processes. ACEE 10(1):117-130

Gaska K, Generowicz A, Zimoch I, Ciuła J, Iwanicka Z (2017) A highperformance computing (HPC) based integrated multithreaded model predictive control (MPC) for water supply networks. ACEE 10(4):141-151

Generowicz A, Kulczycka J, Kowalski Z, Makara A (2011a) Methodology for selection of the location of waste incineration plant on the example of Cracow town. Przem Chem 90:753-758

Generowicz A, Kowalski Z, Kulczycka J, Makara A (2011b) Multicriteria analysis for optimization of sodium chromate production from chromic waste. CLEAN 39:688-696

Georgopoulou E, Hontou V, Gakis N, Sarafidis Y, Mirasgedis S, Lalas DP, Loukatos A, Gargoulas N, Mentzis A, Economidis D, Triantafilopoulos T, Korizi K (2008) BEAsT: a decision-support tool for assessing the environmental benefits and the economic attractiveness of best available techniques in industry. J Clean Prod 16:359-373

Global Industry Analysts Inc (2017) Sodium tripolyphosphate: a global strategic business report. http://www.prweb.com/relea ses/2010/03/prweb3752374.htm. Accessed June 2017

Goberis S, Pundene I, Antonovich V (2005) The effect of sodium tripolyphosphate on the properties of medium-cement refractory castables based on Gorkal-40 cement. Refract Ind Ceram 46:403-408

Gonçalves AA, Ribeiro JLD (2008) Do phosphates improve the seafood quality? Reality and legislation. Pan-Am J Aquatic Sci 3:237-247

Govindan K, Rajendran S, Sarkis J, Murugesan P (2015) Multi criteria decision making approaches for green supplier evaluation and selection: a literature review. J Clean Prod 98:66-83

Hämäläinen RP, Kettunen E (1994) HIPRE 3 + group link user's guide. Helsinki University of Technology. Systems analysis laboratory research reports

Huang IB, Keisler J, Linkov I (2011) Multi-criteria decision analysis in environmental sciences: ten years of applications and trends. Sci Total Environ 409:3578-3594 
Kahraman C (2008) Fuzzy multi-criteria decision making: theory and applications with recent developments. Springer, New York

Kijkowska R, Kowalski Z, Pawłowska-Kozinska D, Wzorek Z, Gorazda K (2007) Effect of impurities $\left(\mathrm{Fe}^{3+}\right.$ and $\left.\mathrm{Al}^{3+}\right)$ on the temperature of sodium tripolyphosphate formation and polymorphic transformation. Ind Eng Chem Res 46:6401-6407

Kowalski Z (2001) Evaluation of options of production process modernization on the example of sodium chromate production process. Pol J Chem Technol 3:20-28

Kowalski Z, Makara A (2014) The synthesis of tripolyphosphate using a one-stage method and a laboratory rotary kiln. Pol J Chem Technol 16:36-40

Kowalski Z, Makara A (2017) Comparison of technologies for the sodium tripolyphosphate production by conventional spray and new one-stage dry methods. Przem Chem 96:187-192

Kowalski Z, Generowicz A, Makara A (2012) Evaluation of municipal waste disposal technologies by BATNEEC. Przem Chem 91:811-815

Kowalski Z, Generowicz A, Makara A, Kulczycka J (2015) Evaluation of municipal waste landfilling using the technology quality assessment method. Environ Prot Eng 41:167-179

Larrodé E, Moreno-Jiménez JM, Muerza MV (2012) An AHP-multicriteria suitability evaluation of technological diversification in the automotive industry. Int J Prod Res 50:4889-4907

Linkov I, Satterstrom FK, Kiker G, Batchelor C, Bridges T, Ferguson E (2006) From comparative risk assessment to multi-criteria decision analysis and adaptive management: recent developments and applications. Environ Int 32:1072-1093
Løken E (2007) Use of multicriteria decision analysis methods for energy planning problems. Renew Sustain Energy Rev 11:1584-1595

Ltifi M, Guefrech A, Mounanga P (2011) Effects of sodium tripolyphosphate addition on early-age physicochemical properties of cement pastes. Proc Eng 10:1457-1462

Makara A, Kowalski Z (2013) Study on production of sodium tripolyphosphate by one-stage dry method using wet-process phosphoric acid. Przem Chem 92:1121-1124

Makara A, Kowalski Z, Banach M (2011) Effect of chemical composition of phosphoric acid on the formation of sodium tripolyphosphate. Przem Chem 90:900-903

Makara A, Smol M, Kulczycka J, Kowalski Z (2016) Technological, environmental and economic assessment of sodium tripolyphosphate production - a case study. J Clean Prod 133:243-251

Mardani A, Jusoh A, Nor KMD, Khalifah Z, Zakwan N, Valipour A (2015) Multiple criteria decision-making techniques and their applications-a review of the literature from 2000 to 2014. Ekon Istraz 28:516-571

Market Research Future (2017) Global sodium tripolyphosphate market research report-forecast to 2022. https://www.marketrese archfuture.com/reports/sodium-tripolyphosphate-market-2319. Accessed 20 June 2017

Matzen M, Alhajji M, Demirel Y (2015) Chemical storage of wind energy by renewable methanol production: feasibility analysis using a multi-criteria decision matrix. Energy 93:343-353 
Maxim A (2014) Sustainability assessment of electricity generation technologies using weighted multi-criteria decision analysis. Energy Policy 65:284-297

Owen DP, Will PA (1992) Sodium chloride and sodium tripolyphosphate effects on characteristics of restructured beef roasts. Tex J Agric Nat Resour 5:113-116

Saaty TL (1980) The analytic hierarchy process. McGraw-Hill, New York

Saaty TL (2001) Decision making for leaders. The analytical hierarchy processes for decision in a complex world. RWS Publications, Pittsburgh
Salo A, Hämäläinen RP (1995) Preference programming through approximate ratio comparisons. Eur J Oper Res 82:458-475

Tan H, Huang J, Ma B, Li X (2014) Effect of superplasticiser and sodium tripolyphosphate on fluidity of cement paste. Mag Concrete Res 66:1194-1200

Toy ADE (1973) The chemistry of phosphorus. Stauffer Chemical Company, New York

Van Wazer JR (1958) Phosphorus and its compounds. Interscience Publishers, New York

Zopounidis C, Doumpos M (2002) Multicriteria classification and sorting methods: a literature review. Eur J Oper Res 138:229-246 